\title{
Competition between flu drugs feverishly anticipated
}

Two new drugs from a novel class of antiviral compounds have reached the marketplace in time for the 1999-2000 flu season: Glaxo Wellcome's (London) Relenza, and Hoffmann-La Roche's (Nutley, NJ) and Gilead Sciences' (Foster City, CA) Tamiflu. As neither product will enjoy the advantage of being first to market, competition will be stiff for the \$1-2 billion worldwide flu market. Some analysts, however, are predicting a competitive advantage for the Gilead/Roche drug.

Both are neuraminidase inhibitors that block viral replication of A and B influenza by preventing the virus from infecting new cells. Both can reduce duration of illness by $25-30 \%$ and severity of symptoms by as much as $40 \%$ and can limit complications (Nature Biotechnology 16, 1002, 1998).

Glaxo's Relenza was approved by the US FDA in July to treat flu in people over 12 years old, and is already approved in Australia and the European Union (EU).

In late September, the Swiss Regulatory Authority granted Roche/Gilead's Tamiflu its first approval, and US FDA approval is expected before the end of October. Thomas Dietz, managing director at Pacific Growth Equities (San Francisco, CA) doesn't anticipate any problems in the approval process because the Roche "data were considerably more robust" than those presented by Glaxo. Roche has also filed for regulatory approval in the EU, but Gilead president and CEO John Martin does not expect a decision in time for the upcoming flu season.

However, Roche could enjoy a potential marketing advantage among elderly patients, including the 2.2 million residents in US nursing homes: Britain's National Institute for Clinical Excellence (NICE) in October recommended that the UK National Health Service not provide reimbursement for Glaxo's Relenza in elderly patients, prompting a $2 \%$ drop in Glaxo's stock price to $\mathfrak{E} 15.55$ (US\$25.71). In clinical studies targeting elderly populations, Roche's data on Tamiflu were "substantially better," notes Dietz.

In addition, Gilead/Roche's pill formulation offers a significant advantage in terms of patient convenience over Glaxo's inhaled drug. The vast majority of people would "rather just pop a pill," says Dietz. Although Glaxo is promoting Relenza as a localized

Vicki Glaser is a freelance writer working in Allentown, PA. treatment for a localized disease, the drug's efficacy "depends on the ability to use the inhaler properly," says Caroline Copithorne, senior biotechnology analyst at Prudential Securities (New York). Dietz concurs that "reservations about the inhaler device" linger, and problems with the use of the device might account for Relenza's failure to demonstrate effectiveness in Glaxo's US clinical studies.

Tamiflu represents an important success story for both Gilead and the biotechnology sector, which has seen few new drugs come to market in recent months. Although not a make-or-break drug for Gilead-which already has three products on the market, including AmBisome (annual sales exceed $\$ 100$ million; Nat. Biotechnol. 17, 316) Tamiflu will yield substantial revenues for the company. Dietz projects initial sales of

\section{Some analysts are predict-} ing a competitive advantage for the Gilead/Roche drug.

\$75-100 million for Tamiflu this flu season, with that figure rising steadily in subsequent years and peaking at about $\$ 500$ million.

Meanwhile, both Gilead/Roche and Glaxo face a significant challenge in marketing these drugs-educating consumers about how to recognize flu symptoms, and, with the drugs' 48 hour window of efficacy, the importance of seeking treatment early. The recent availability of rapid, point-of-care diagnostic tests for influenza could help. In September, for instance, Quidel (San Diego, CA), a manufacturer of rapid immunodiagnostic products, received FDA approval of its QuickVue influenza test.

And both Glaxo and Gilead/Roche have a keen interest in the flu prevention market, which could eventually prove even larger than the therapeutic market. Both companies have completed prophylactic studies, and Copithorne expects them to add prophylactic indications next year. At the 39th Interscience Conference on Antimicrobial Agents and Chemotherapy in Septermber, Glaxo reported that Relenza reduced the risk of acquiring influenza from an infected family member by $79 \%$ compared to placebo. And Roche has shown that prophylactic use of Tamiflu is associated with significant antiviral effects (J. Am. Med. Assoc. 282, 1240).

Vicki Glaser 